\title{
DAMPAK KEGIATAN PELEDAKAN PERTAMBANGAN ANDESIT TERHADAP LINGKUNGAN PEMUKIMAN DI GUNUNG SUDAMANIK KECAMATAN CIGUDEG KABUPATEN BOGOR \\ (The Impact of Blasting Activities for Andesite Mining to Residential Enivironment at Mount Sudamanik Cigudeg Subdistrict Bogor Regency)
}

\author{
Aljon Albertus Manotar Simbolon ${ }^{1 *}$, Muhamad Yani ${ }^{1}$ dan Irzaman $^{2}$ \\ ${ }^{1}$ Program Pengelolaan Sumberdaya Alam dan Lingkungan, Program Pascasarjana, \\ Institut Pertanian Bogor, Jalan Pajajaran, Kampus IPB Baranangsiang, Bogor 16151. \\ ${ }^{2}$ Jurusan Fisika, Fakultas Matematika dan Ilmu Pengetahuan Alam, \\ Institut Pertanian Bogor, Jalan Meranti, Kampus IPB Dramaga, Bogor 16680. \\ *Penulis korespondensi. No Tel: 08161919153. Email: aljondistam@yahoo.com.
}

Diterima: 25 Maret 2015

Disetujui: 5 Mei 2015

\begin{abstract}
Abstrak
Aspek lingkungan hidup kemungkinan terganggu akibat kegiatan eksploitasi sumber daya alam. Mineral dan batuan sebagai salah satu sumber daya alam pada umumnya tersebar di daerah terpencil yang masih memerlukan pengembangan. Pada sisi ini, kehadiran perusahaan pertambangan sangat penting peranannya bagi kemajuan dan pembangunan serta meretas keterisolasian suatu daerah. Wilayah sekitar Gunung Sudamanik, Kecamatan Cigudeg, Kabupaten Bogor tumbuh dan berkembang karena pertambangan andesit. Gunung Sudamanik telah dan masih dieksploitasi lima perusahaan tambang andesit yang memiliki Izin Usaha Pertambangan (IUP) dengan luas total Wilayah Izin Usaha Pertambangan (WIUP) seluas 113 hektar. Pada tahun 2012, total produksi batuan kelima perusahaan adalah 3.984.785 ton atau rata-rata 332.065,4 ton per bulan. Produksi batuan tersebut dihasilkan dari peledakan yang dapat mencapai lima kali peledakan atau lebih setiap hari. Getaran dan bunyi ledakan yang disebabkan peledakan ini kemungkinan berdampak terhadap lingkungan hidup, terutama pada konstruksi rumah dan kenyamanan masyarakat yang bermukim di sekitar kaki Gunung Sudamanik. Pemukiman penduduk yang paling dekat lokasi peledakan andesit berada pada tiga kampung/dusun yaitu Kampung Kadaung, Lebakwangi Lapangan dan Lebakwangi Girang. Ketiga kampung tersebut secara administratif berada dalam Desa Rengasjajar. Rumah warga pada pemukiman yang paling dekat ke lokasi peledakan batuan andesit berjarak sekitar 337 - 616 meter. Hasil penelitian menunjukkan bahwa pemakaian 90,5 kg bahan peledak delay yang sama pada jarak $148 \mathrm{~m}$ mengakibatkan tingkat getaran tanah maksimum 7,71 mm/s yang telah melewati baku mutu kelas 3 SNI 7571 : 2010. Dan pemakaian bahan peledak mulai dari 77,4 kg sampai 1310,4 kg setiap peledakan tidak menimbulkan dampak kebisingan pada pemukiman warga.
\end{abstract}

Kata kunci: baku mutu, bunyi ledakan, getaran tanah, kenyamanan masyarakat, lingkungan hidup

\begin{abstract}
Living environment aspects are possibility disrupted by the exploitation of natural resources. Minerals and rocks as one of the natural resources in general are scattered in remote areas that still need development. On this side, the presence of mining companies is important for the progress and development as well as rip off the isolation area. The region around Mount Sudamanik, Cigudeg District, Bogor Regency grows due to the mining of andesite rock. Mount Sudamanik has been and is being mined out by five companies that have mining business license (IUP) covering an area of 113 hectares of region mining business permit (WIUP). In 2012, total andesite production of the all company reached 3,984,785 tons, or an average of 332,065.4 tons per month. Production of these andesite generated from blasting that can reach five times the blasting or more every day. Ground vibrations and air blast caused by blasting probably effect to the living environment, mainly to the house construction and comfort communities who resides around the foot of Mount Sudamanik. Three villages are situated at the nearest the andesite mining inculuding Kampung Kadaung, Lebakwangi Lapangan and Lebakwangi Girang. Residential homes on the nearest location to the andesite blasting is about 337- 616 meters. The results showed that the use of $90.5 \mathrm{~kg}$ of explosives same delay at distance 148 resulted in maximum ground vibration levels of $7.71 \mathrm{~m} / \mathrm{s}$ that have full filled the quality standard of the third grade SNI 7571: 2010. And the use of explosives ranging from $77.4 \mathrm{~kg}$ to $1310.4 \mathrm{~kg}$ blasting did not cause any noise impact on residential areas.
\end{abstract}

Keywords: air blast, comfort communities, ground vibration, living environment, quality standard

\section{PENDAHULUAN}

Aspek lingkungan hidup di Indonesia sering kali dipinggirkan dalam pelaksanaan pembangunan demi memacu pertumbuhan ekonomi untuk kesejahteraan sosial dan kemapanan budaya. Hal ini terlihat dari dominannya aspek ekonomi dan sosial 
budaya dalam perencanaan dan penetapan sebuah kebijakan. Menurut Sugandhy dan Hakim (2007) pola pembangunan perlu memperhatikan fungsi sumberdaya alam dan sumberdaya manusia, agar proses pembangunan terlaksana secara berkelanjutan. Mengingat pemerintah memegang peranan strategis dalam penetapan kebijakan pembangunan, maka salah satu konsep yang diharapkan dapat menjadikan aspek lingkungan sebagai mainstream pembangunan di Indonesia bersama-sama dengan aspek ekonomi dan sosial budaya adalah konsep kepemerintahan lingkungan (environmental governance). Menurut Keraf (2010) ada korelasi sangat positif antara penyelenggaraan pemerintahan dengan pengelolaan lingkungan hidup, di mana pemerintahan yang buruk akan menciptakan pengelolaan lingkungan hidup yang buruk pula, dan pemerintahan yang baik akan menghasilkan pengelolaan yang baik juga.

Kehadiran usaha pertambangan memang diakui sangat penting peranannya bagi kemajuan dan pembangunan serta meretas keterisolasian suatu daerah. Bahkan beberapa kota, seperti Sawahlunto di Sumatera Barat, Pangkal Pinang di Pulau Bangka telah berkembang dan hidup dari rangkaian kegiatan pertambangan. Sawahlunto berkembang menjadi kota yang ramai karena adanya pertambangan batubara Ombilin, sementara Pangkal Pinang tumbuh karena adanya pertambangan timah (Sudradjat 2007).

Gunung Sudamanik telah dan masih dieksploitasi lima perusahaan tambang batu andesit yang memiliki Izin Usaha Pertambangan (IUP) dengan luas total Wilayah Izin Usaha Pertambangan (WIUP) seluas 113 hektar. Pada tahun 2012, total produksi batuan kelima perusahaan adalah 3.984.785 ton atau rata-rata 332.065,4 ton per bulan. Kegiatan pertambangan batuan andesit memiliki salah satu rangkaian kegiatan utama yaitu peledakan untuk memberaikan batuan andesit menjadi bongkahan-bongkahan batuan (fragmentasi). Fragmentasi batuan andesit inilah yang menjadi produksi atau hasil peledakan yang diinginkan perusahaan pertambangan andesit.

Produksi andesit dihasilkan dari penggunaan sejumlah bahan peledak. Perbandingan antara kuantitas bahan peledak (kg) yang digunakan dengan produksi batuan andesit (ton) hasil peledakan diistilahkan sebagai powder factor. Sebagai gambaran bahwa semakin besar bahan peledak yang digunakan akan semakin besar produksi andesit hasil peledakan. Powder factor cenderung mengarah pada nilai ekonomis suatu kegiatan peledakan karena berkaitan dengan harga bahan peledak yang dibeli dan produksi batuan yang dihasilkan untuk dijual perusahaan tambang. Untuk mengetahui pengaruh kuantitas bahan peledak terhadap produksi andesit yang dihasilkannya, maka menurut Jullien dkk.(2012) rentang waktu satu tahun dianggap sebagai masa waktu yang ideal untuk mempelajari dan memahami seluk-beluk produksi pertambangan yang menghasilkan agregat seperti pertambangan batuan andesit.

Persoalan lingkungan hidup yang mempengaruhi kenyamanan masyarakat sekitar Gunung Sudamanik, seperti getaran tanah, kebisingan bunyi ledakan, dan terjadinya lontaran bongkahan batuan (flyrock) yang dapat mengancam keselamatan jiwa, sering dikaitkan sebagai dampak negatif kegiatan pertambangan yang menerapkan peledakan sebagai salah satu rangkaian kegiatan untuk meningkatkan produksi andesit. Menurut Kecojevic dan Radomsky (2005) flyrock dan kurangnya pengamanan pada zona peledakan telah menyebabkan 281 kecelakaan pada tambang terbuka (surface mining) antara tahun 1978 dan 1998. Di sisi lain, peledakan merupakan satusatunya cara yang paling efektif untuk membongkar dan memecahkan batuan andesit dalam rangka mencapai produksi yang tinggi.

Pemukiman penduduk yang paling dekat lokasi peledakan andesit berada pada tiga kampung/dusun yaitu Kampung Kadaung, Lebakwangi Lapangan dan Lebakwangi Girang. Ketiga kampung tersebut secara administratif berada dalam Desa Rengasjajar. Rumah warga pada pemukiman yang paling dekat ke lokasi peledakan batuan andesit berjarak sekitar 337 - 616 meter.

Dengan berlakunya UU Nomor 4 Tahun 2009 tentang Pertambangan Mineral dan Batubara (UU Minerba) serta UU Nomor 32 Tahun 2009 tentang Perlindungan dan Pengelolaan Lingkungan Hidup, ditekankan keberpihakan yang cukup besar terhadap kelestarian fungsi lingkungan atau nuansa ecocentric sangat kuat. Menurut Sumardjono dkk. (2011), UU Minerba memberikan perhatian yang seimbang, baik terhadap peningkatan produksi maupun terhadap konservasi sumber daya mineral dan batubara serta konservasi lingkungan. Alasan peningkatan produksi pertambangan tidak bisa mengalahkan kelestarian lingkungan. Dengan demikian rumusan masalah yang akan dikaji dalam penelitian ini meliputi seberapa besar pengaruh kuantitas pemakaian bahan peledak (handak) dan jarak terhadap getaran tanah dan intensitas bunyi ledakan di sekitar pemukiman di Gunung Sudamanik.

Penelitian ini bertujuan untuk mengkaji dampak getaran tanah dan bunyi ledakan yang diakibatkan kegiatan peledakan pertambangan andesit terhadap kenyamanan masyarakat yang bermukim di sekitar Gunung Sudamanik. Pengumpulan data kuantitas pemakaian bahan 
peledak, pengukuran jarak titik ledak ke pemukiman warga, pengukuran tingkat getaran tanah dan taraf intensitas bunyi ledakan. Data yang terkumpul diolah untuk mendapatkan pola hubungan antara kuantitas bahan peledak dan jarak terhadap tingkat getaran tanah, serta pola hubngan anatara kuantitas bahan peledak dan jarak terhadap taraf intensitas bunyi ledakan. Dari pola hubungan tersebut dapat ditentukan pemakaian bahan peledak maksimum agar tingkat getaran dan intensitas bunyi ledakan tidak melewati batas nilai baku mutu sehingga lingkungan pemukiman warga sekitar pertambangan masih nyaman dihuni.

\section{METODE PENELITIAN}

\section{Waktu dan Lokasi}

Penelitian dilaksanakan dari bulan Januari sampai April 2013 yang berlokasi di Gunung Sudamanik, Desa Rengasjajar, Kecamatan Cigudeg, Kabupaten Bogor. Andesit pada Gunung Sudamanik dieksploitasi oleh lima perusahaan tambang batuan andesit yang memiliki Izin Usaha Pertambangan (IUP). Luas total Wilayah Izin Usaha Pertambangan (WIUP) adalah 113 hektar. Bahan dan peralatan penelitian terdiri dari bahan peledak yang meliputi Ammonium Nitrat Fuel Oil (ANFO), dinamit dan detonator serta kabel-kabel sambungan detonator antar lubang ledak. Untuk membuat lubang ledak berdiameter 3 in digunakan mesin bor. Selanjutnya digunakan blasting machine untuk memicu ledakan detonator. Lembar formulir isian digunakan untuk mencatat pengeluaran dan pemakaian bahan peledak. Penentuan titik koordinat dan jarak dua titik digunakan GPS navigasi. Sedangkan untuk mengukur tingkat getaran tanah dan intensitas bunyi ledakan digunakan seismograf minimate plus. Untuk menganalisis data digunakan software Minitab dan Chart Excel.

\section{Teknik Pengumpulan Data}

Menurut Sugiyono (2011) pendekatan kuantitatif dipilih jika penelitian diinginkan untuk menunjukkan hubungan antar variabel, menguji teori dan mencari generalisasi yang mempunyai nilai prediktif. Oleh sebab itu pengumpulan data yang diterapkan dalam penelitian ini adalah pendekatan kuantitatif dengan melakukan pengukuran langsung pada lokasi peledakan batuan andesit. Setiap sekali peledakan dikumpulkan empat macam data yang meliputi kuantitas bahan peledak, jarak antara titik ledakan ke lokasi minimate, tingkat getaran tanah dan intensitas bunyi yang diakibatkan peledakan. Keempat macam data ini merupakan data primer yang dikumpulkan dari lokasi peledakan batuan andesit.
Teknik Analisis Data

Analisis pengaruh kuantitas bahan peledak dan jarak terhadap tingkat getaran tanah

Analisis kuantitas bahan peledak dan jarak terhadap getaran tanah, dicoba menerapkan analyze response surface dengan menggunakan software Minitab. Ada empat macam model analisis yang tersedia pada software, yaitu: linier, linier dan interaksi, linier dan kuadrat, serta kuadrat lengkap. Model persamaan yang sesuai adalah model yang mempunyai galat koefisien regresi dan galat ANOVA yang lebih kecil dari taraf nyata 5\% serta mempunyai koefisien determinasi $\mathrm{R}^{2}$ lebih besar dari $80 \%$. Jika tidak ada model yang sesuai, analisis dilanjutkan dengan menggunakan persamaan $\mathrm{Du}$ Pont

$$
Y=1048\left(\frac{X_{2}}{X_{1}^{0,5}}\right)^{-1,6}
$$

dengan $\mathrm{Y}=$ tingkat getaran $(\mathrm{mm} /$ detik $), \mathrm{X}_{1}=$ maksimum delay handak $(\mathrm{kg})$ dan $\mathrm{X}_{2}=$ jarak (m). Jika persamaan Du Pont juga belum sesuai, maka persamaan (1) dimodifikasi untuk mencari koefisien yang cocok agar bisa memodelkan hubungan kuantitas bahan peledak dan jarak terhadap tingkat getaran.

Selanjutnya data getaran dibandingkan dengan baku mutu SNI 7571:2010. Jika tingkat getaran di atas baku mutu, maka perusahaan tambang mesti merubah rancangan peledakan agar getaran aman terhadap bangunan. Menurut Amnieh dkk. (2010) bahwa tingkat getaran tidak hanya dipengaruhi kuantitas bahan peledak, tapi juga dipengaruhi oleh banyaknya lubang ledak. Artinya pada kuantitas bahan peledak yang sama namun terdiri dari jumlah ledak yang berbeda, ternyata mengakibatkan getaran yang berbeda pula.

\section{Analisis pengaruh kuantitas bahan peledak dan jarak terhadap taraf intensitas (TI) bunyi ledakan}

Analisis kuantitas bahan peledak dan jarak terhadap TI bunyi ledakan, dicoba menerapkan analyze response surface dengan menggunakan software Minitab. Ada empat macam model analisis yang tersedia pada software, yaitu: linier, linier dan interaksi, linier dan kuadrat, serta kuadrat lengkap. Model persamaan yang sesuai adalah model yang mempunyai galat koefisien regresi dan galat ANOVA yang lebih kecil dari taraf nyata 5\% serta mempunyai koefisien determinasi $\mathrm{R}^{2}$ lebih besar dari $80 \%$.

Jika tidak ada model yang sesuai, analisis dilanjutkan dengan menggunakan persamaan bahwa hubungan antara TI bunyi dengan jarak adalah berbentuk logaritma. Menurut Tipler (1991) TI bunyi memenuhi persamaan

$\mathrm{TI}_{2}=\mathrm{TI}_{1}-20 \log \left(\mathrm{r}_{2} / \mathrm{r}_{1}\right)$ 
Di mana $r_{1}$ dan $r_{2}$ adalah jarak pertama dan jarak kedua dari suatu sumber bunyi, sedangkan $\mathrm{TI}_{1}$ dan $\mathrm{TI}_{2}$ masing-masing merupakan taraf intensitas bunyi pada jarak $r_{1}$ dan $r_{2}$. Sumber bunyi adalah ledakan udara yang dihasilkan oleh sejumlah tertentu bahan peledak. Hasil pengukuran pada $\mathrm{r}_{2}$ merupakan $\mathrm{TI}_{2}$ pengukuran akan diuji t dengan $\mathrm{TI}_{2}$ yang dihitung dengan menggunakan Persamaan (2).

\section{HASIL DAN PEMBAHASAN}

\section{Pengaruh Kuantitas Bahan Peledak dan Jarak Terhadap Tingkat Getaran}

Apabila gelombang seismik akibat dari peledakan merambat melalui tanah, maka partikel tanah akan bergetar atau bergerak dari posisi semula ke posisi lain dan kembali ke posisi semula sebagai titik setimbangnya. Getaran tanah terjadi pada daerah elastis, sebab material tanah pada daerah elastis menerima tegangan yang lebih kecil dari kekuatan material tanah itu sendiri sehingga hanya menyebabkan perubahan bentuk dan volume saja (Sudarmono 2008). Partikel yang bergerak akan mempunyai perpindahan, kecepatan dan percepatan.

Menurut Sudarmono dan Kadir (2009) dua faktor utama yang mempengaruhi tingkat getaran tanah akibat peledakan adalah kuantitas (jumlah) bahan peledak dan jarak suatu tempat ke titik ledakan. Demikian juga menurut Nicholls dkk. (1971) dalam Kartodharmo (1990) tingkat getaran peledakan dipengaruhi dua faktor prinsip yaitu muatan maksimum bahan peledak pada nomor delay detonator yang sama dan jarak. Sebagai contoh pada Tabel 1, kuantitas bahan peledak yang dipakai dalam sekali peledakan sebanyak 1310,4 $\mathrm{kg}$, namun yang mempengaruhi tingkat getaran adalah 151,2 kg yang merupakan jumlah maksimum bahan peledak pada delay detonator yang sama.

Pemakaian beberapa macam nomor delay detonator bertujuan untuk terjadinya peledakan tunda (delay blasting) sebagai cara pengendalian tingkat getaran tanah agar tidak mengganggu lingkungan pemukiman masyarakat. Peledakan sejumlah bahan peledak terbagi menjadi beberapa

Tabel 1. Tingkat getaran hasil pengukuran, hasil persamaan (1) dan modifikasinya.

\begin{tabular}{|c|c|c|c|c|c|c|c|}
\hline \multirow{2}{*}{$\begin{array}{c}\text { Total } \\
\text { handak } \\
(\mathrm{kg})\end{array}$} & \multirow{2}{*}{$\begin{array}{c}\text { Handak } \\
\text { delay } \\
\text { (kg) }\end{array}$} & \multirow{2}{*}{$\begin{array}{c}\text { Jarak } \\
\text { (m) }\end{array}$} & \multicolumn{2}{|c|}{ Getaran } & \multirow{2}{*}{$\begin{array}{l}\text { Pembagian } \\
\text { kedua } \\
\text { getaran }\end{array}$} & \multirow{2}{*}{$\begin{array}{c}\text { Hasil bagi } \\
\text { dikali } \\
1048\end{array}$} & \multirow{2}{*}{$\begin{array}{l}\text { Getaran modifikasi } \\
\text { persamaan } \\
(1)(\mathrm{mm} / \mathrm{s})\end{array}$} \\
\hline & & & $\begin{array}{l}\text { Hasil pengu- } \\
\text { kuran (mm/s) }\end{array}$ & $\begin{array}{c}\text { Perhitungan persa- } \\
\text { maan }(1)(\mathrm{mm} / \mathrm{s})\end{array}$ & & & \\
\hline 907,2 & 100,8 & 622 & 0,00 & 1,55 & 0,00 & 0,00 & 0,50 \\
\hline 362,0 & 90,5 & 148 & 7,71 & 14,16 & 0,54 & 570,78 & 4,52 \\
\hline 229,8 & 76,6 & 429 & 0,76 & 2,26 & 0,34 & 352,92 & 0,72 \\
\hline 128,0 & 51,2 & 213 & 1,07 & 5,01 & 0,21 & 223,71 & 1,60 \\
\hline 77,4 & 25,8 & 209 & 1,34 & 2,99 & 0,45 & 470,28 & 0,95 \\
\hline 154,2 & 151,4 & 354 & 0,87 & 5,29 & 0,16 & 172,24 & 1,69 \\
\hline 604,8 & 100,8 & 473 & 1,46 & 2,40 & 0,61 & 636,32 & 0,77 \\
\hline 604,8 & 100,8 & 447 & 1,34 & 2,63 & 0,51 & 533,51 & 0,84 \\
\hline 442,4 & 61,0 & 831 & 0,66 & 0,65 & 1,01 & 1059,15 & 0,21 \\
\hline 128,6 & 71,4 & 260 & 0,51 & 4,75 & 0,11 & 112,43 & 1,52 \\
\hline 465,6 & 179,1 & 430 & 0,45 & 4,44 & 0,10 & 106,32 & 1,42 \\
\hline 102,4 & 34,1 & 230 & 0,56 & 3,20 & 0,17 & 183,26 & 1,02 \\
\hline 180,2 & 42,9 & 283 & 0,43 & 2,76 & 0,16 & 163,18 & 0,88 \\
\hline 362,6 & 69,1 & 515 & 2,19 & 1,55 & 1,41 & 1479,34 & 0,50 \\
\hline 756,0 & 100,8 & 563 & 0,95 & 1,82 & 0,52 & 547,12 & 0,58 \\
\hline 180,2 & 69,3 & 283 & 0,57 & 4,05 & 0,14 & 147,39 & 1,29 \\
\hline 103,0 & 54,9 & 158 & 1,28 & 8,55 & 0,15 & 156,93 & 2,73 \\
\hline 229,8 & 76,6 & 316 & 1,59 & 3,68 & 0,43 & 452,72 & 1,18 \\
\hline 205,0 & 82,0 & 296 & 0,00 & 4,32 & 0,00 & 0,00 & 1,38 \\
\hline 438,8 & 95,4 & 481 & 2,16 & 2,24 & 0,96 & 1010,56 & 0,72 \\
\hline 907,2 & 100,8 & 612 & 0,91 & 1,59 & 0,57 & 598,95 & 0,51 \\
\hline 380,2 & 58,5 & 318 & 0,53 & 2,94 & 0,18 & 189,13 & 0,94 \\
\hline 380,2 & 58,5 & 308 & 0,46 & 3,09 & 0,15 & 155,97 & 0,99 \\
\hline 177,4 & 88,1 & 231 & 1,04 & 6,80 & 0,15 & 160,38 & 2,17 \\
\hline 177,4 & 88,1 & 223 & 1,27 & 7,19 & 0,18 & 185,11 & 2,30 \\
\hline 266,1 & 59,1 & 353 & 0,48 & 2,51 & 0,19 & 200,78 & 0,80 \\
\hline 266,1 & 59,1 & 363 & 0,00 & 2,40 & 0,00 & 0,00 & 0,77 \\
\hline 193,5 & 51,6 & 201 & 1,85 & 5,53 & 0,33 & 350,33 & 1,77 \\
\hline 193,5 & 51,6 & 164 & 4,12 & 7,66 & 0,54 & 563,43 & 2,45 \\
\hline 1310,4 & 151,2 & 1100 & 0,00 & 0,86 & 0,00 & 0,00 & 0,28 \\
\hline \multirow[t]{2}{*}{1310,4} & 151,2 & 655 & 1,01 & 1,98 & 0,51 & 535,77 & 0,63 \\
\hline & \multicolumn{5}{|c|}{ Rata-rata } & 365 & \\
\hline
\end{tabular}


seri muatan bahan peledak yang lebih kecil. Getaran tanah yang diakibatkan peledakan pada akhirnya terdiri dari bagian-bagian getaran yang kecil. Peledakan tunda menyebabkan berkurangnya tingkat getaran tanah karena masing-masing delay hanya mengakibatkan gelombang seismik berenergi kecil yang saling terpisah, di mana gelombang seismik yang diakibatkan delay sebelumnya telah merambat pada jarak tertentu, baru menyusul gelombang delay berikutnya.

Menurut Du Pont (1977) dalam Kartodharmo (1990), tingkat getaran berbanding lurus dengan jumlah maksimum delay bahan peledak berpangkat 0,8 dan berbanding terbalik dengan jarak berpangkat 1,6, sebagaimana persamaan (1). Tingkat getaran hasil pengukuran dan tingkat getaran hasil persamaan (1) seperti pada Tabel 1 akan diuji apakah kedua tingkat getaran berbeda atau sama pada taraf nyata $5 \%$. Kalau berbeda maka koefisien dari persamaan (1) harus dimodifikasi dan dicari nilainya sehingga menjadi persamaan yang dapat mewakili tingkat getaran peledakan. Validitas tingkat getaran hasil dari rumus baru, diuji kembali bahwa kedua tingkat getaran (hasil pengukuran dan hasil persamaan baru) berbeda atau sama pada taraf nyata $5 \%$. Bila hasil uji menunjukkan bahwa kedua tingkat getaran sama, maka persamaan baru tersebut menjadi persamaan yang dapat mewakili tingkat getaran peledakan.

Dari uji t pada taraf nyata 0,05 dihasilkan bahwa tingkat getaran hasil pengukuran tidak berbeda dengan tingkat getaran hasil modifikasi persamaan Du Pont. Dengan demikian persamaan untuk memodelkan pengaruh kuantitas bahan peledak dan jarak terhadap tingkat getaran akibat peledakan andesit memenuhi persamaan

$$
Y=365\left(\frac{X_{2}}{X_{1}{ }^{0,5}}\right)^{-1,6}
$$

Persamaan (3) digunakan untuk menaksir jumlah maksimum delay bahan peledak $\left(\mathrm{X}_{1}\right)$, sehingga persamaan menjadi

$$
X_{1}=X_{2}^{2}\left(\frac{Y}{365}\right)^{1,25}
$$

Di mana $\mathrm{X}_{2}$ sebagai jarak terdekat titik ledak ke pemukiman warga dan $\mathrm{Y}$ sebagai tingkat getaran mendekati baku mutu menurut SNI 7571: 2010. Jenis bangunan di sekitar daerah peledakan andesit dapat diklasifikan pada kelas 2 dan kelas 3 dalam SNI 7571: 2010 dengan baku mutu tingkat getaran masing-masing $3 \mathrm{~mm} / \mathrm{s}$ dan $5 \mathrm{~mm} / \mathrm{s}$. Dengan memasukkan $\mathrm{Y}=2,9 \mathrm{~mm} / \mathrm{s}(0,1$ poin di bawah baku mutu kelas 2) maka akan diperoleh persamaan

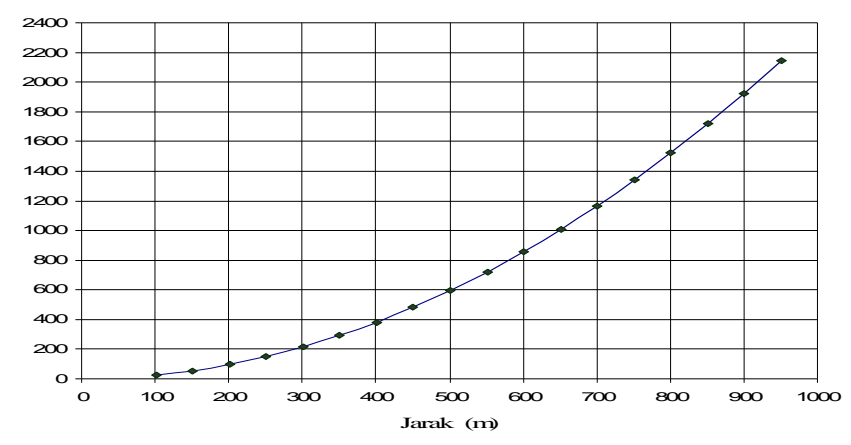

Gambar 1. Model kuantitas handak vs jarak pada tingkat getar tertentu.

$$
\mathrm{X}_{1}=\mathbf{0 , 0 0 2 4 \mathrm { X } _ { 2 } ^ { 2 }}
$$

Model dari persamaan (5) ini diperlihatkan pada Gambar 1.

Gambar 1 menunjukkan bahwa pemakaian bahan peledak pada delay maksimum di atas kurva akan menyebabkan tingkat getar melewati baku mutu kelas 2. Sebagai contoh, pemakaian bahan peledak lebih banyak dari $400 \mathrm{~kg}$ pada jarak $400 \mathrm{~m}$ dari pemukiman akan menyebabkan tingkat getaran melewati baku mutu $3 \mathrm{~mm} / \mathrm{s}$. Untuk pemakaian bahan peledak lebih sedikit dari $400 \mathrm{~kg}$ pada jarak $400 \mathrm{~m}$, maka tingkat getarannya masih di bawah baku mutu $3 \mathrm{~mm} / \mathrm{s}$. Jadi rekomendasi kuantitas pemakaian bahan peledak harus berada di bawah kurva agar tingkat getaran tanah akibat peledakan tidak menimbulkan keresahan masyarakat yang bermukim di sekitar pertambangan andesit.

\section{Pengaruh Kuantitas Bahan Peledak dan Jarak Terhadap TI Bunyi Ledakan}

Menurut Marmer dkk. (2010) meskipun air blast jarang mengakibatkan kerusakan bangunan, kebisingan dapat mengakibatkan ketidaknyamanan. TI yang dihasilkan bunyi atau suara mengikuti persamaan (2). Hasil pengukuran TI bunyi ledakan dan hasil perhitungan menggunakan persamaan (2) diperlihatkan pada Tabel 2.

Hasil uji t menghasilkan bahwa bahwa $P$ value $=0,602$ lebih besar dari taraf nyata 0,05 , yang berarti bahwa TI bunyi ledakan hasil pengukuran tidak berbeda dengan TI bunyi ledakan hasil perhitungan rumus. Dengan demikian dalam kasus ini rumus intensitas dapat digunakan untuk memperkiran $\mathrm{TI}_{2}$ pada berbagai jarak yang diinginkan dari berbagai variasi jumlah bahan peledak yang dipakai dalam penelitian ini. Semua hasil pengukuran taraf intensitas pada penelitian ini menjadi $\mathrm{TI}_{1}$ pada masing-masing jumlah bahan peledak, dan akan diperkirakan $\mathrm{TI}_{2}$ pada berbagai kemungkinan jarak titik peledakan ke kantor tambang atau ke pemukiman warga. Hasil perkiraan $\mathrm{TI}_{2}$ diperlihatkan pada Tabel 3. 
Tabel 2. TI bunyi ledakan hasil pengukuran dan perhitungan rumus intensitas

\begin{tabular}{cccccc}
\hline Kuantitas handak $(\mathrm{kg})$ & TI1 pengukuran $(\mathrm{dB} \mathrm{L})$ & $\mathrm{r}_{1(\mathrm{~m})}$ & $\mathrm{r}_{2}(\mathrm{~m})$ & \multicolumn{2}{c}{ TI2 $(\mathrm{dB} \mathrm{L})$} \\
\cline { 5 - 6 } & & & & Pengukuran & Dihitung persamaan $(5)$ \\
\hline 128,6 & 112,6 & 260 & 283 & 115 & 111,9 \\
177,4 & 117,4 & 231 & 223 & 119 & 117,7 \\
193,5 & 120,5 & 201 & 164 & 125,4 & 122,3 \\
229,8 & 112,8 & 429 & 316 & 114,4 & 115,5 \\
380,2 & 125,0 & 318 & 308 & 123,4 & 125,3 \\
604,8 & 108,0 & 473 & 447 & 107,0 & 108,5 \\
\hline
\end{tabular}

Tabel 3. Perkiraan TI bunyi ledakan pada berbagai jarak

\begin{tabular}{|c|c|c|c|c|c|c|c|c|c|}
\hline \multirow[t]{2}{*}{$\begin{array}{l}\text { Kuantitas } \\
\text { handak (kg) }\end{array}$} & \multirow{2}{*}{\multicolumn{2}{|c|}{$\begin{array}{c}\text { Jarak titik } \\
\text { ledak ke titik } \\
\text { minimate (m) }\end{array}$}} & \multirow[t]{2}{*}{ TI1 (dB L) } & \multicolumn{6}{|c|}{$\begin{array}{l}\text { Perkiraan TI2 (dB L), pada jarak titik ledak ke kantor } \\
\text { tambang atau ke pemukiman }\end{array}$} \\
\hline & & & & $200 \mathrm{~m}$ & $337 \mathrm{~m}$ & $400 \mathrm{~m}$ & $462 \mathrm{~m}$ & $500 \mathrm{~m}$ & $616 \mathrm{~m}$ \\
\hline 77,4 & \multicolumn{2}{|c|}{209} & 115,7 & 116,1 & 111,6 & 110,1 & 108,8 & 108,1 & 106,3 \\
\hline 102,4 & \multicolumn{2}{|r|}{230} & 115,0 & 116,2 & 111,7 & 110,2 & 108,9 & 108,3 & 106,4 \\
\hline 103,0 & \multicolumn{2}{|r|}{158} & 121,4 & 119,4 & 114,8 & 113,3 & 112,1 & 111,4 & 109,6 \\
\hline 128,0 & \multicolumn{2}{|r|}{213} & \multirow{2}{*}{116,1} & 116,6 & 112,1 & 110,6 & 109,4 & 108,7 & 106,9 \\
\hline 128,6 & \multirow{2}{*}{\multicolumn{2}{|c|}{$\begin{array}{l}283 \\
354\end{array}$}} & & 118,0 & 113,5 & 112,0 & 110,7 & 110,1 & 108,2 \\
\hline 154,2 & & & 120,0 & 125,0 & 120,4 & 118,9 & 117,7 & 117,0 & 115,2 \\
\hline 177,4 & \multicolumn{2}{|r|}{223} & 119,0 & 119,9 & 115,4 & 113,9 & 112,7 & 112,0 & 110,2 \\
\hline 180,2 & & 283 & 123,0 & 126,0 & 121,5 & 120,0 & 118,7 & 118,1 & 116,2 \\
\hline 193,5 & & 164 & 125,4 & 123,7 & 119,1 & 117,7 & 116,4 & 115,7 & 113,9 \\
\hline 229,8 & & 316 & 114,4 & 118,4 & 113,8 & 112,4 & 111,1 & 110,4 & 108,6 \\
\hline 266,1 & & 353 & 88,0 & 92,9 & 88,4 & 86,9 & 85,7 & 85,0 & 83,2 \\
\hline 362,0 & & 148 & 123,1 & 120,5 & 116,0 & 114,5 & 113,2 & 112,5 & 110,7 \\
\hline 362,6 & & 515 & 103,5 & 111,7 & 107,2 & 105,7 & 104,4 & 103,8 & 101,9 \\
\hline 380,2 & & 318 & 125,0 & 129,0 & 124,5 & 123,0 & 121,8 & 121,1 & 119,3 \\
\hline 438,8 & & 481 & 110,2 & 117,8 & 113,3 & 111,8 & 110,6 & 109,9 & 108,1 \\
\hline 442,4 & & 831 & 102,8 & 115,2 & 110,6 & 109,2 & 107,9 & 107,2 & 105,4 \\
\hline 465,6 & & 430 & 124,5 & 131,1 & 126,6 & 125,1 & 123,9 & 123,2 & 121,4 \\
\hline 604,8 & & 473 & 108,0 & 115,5 & 110,9 & 109,5 & 108,2 & 107,5 & 105,7 \\
\hline 756,0 & & 563 & 121,6 & 130,6 & 126,1 & 124,6 & 123,3 & 122,6 & 120,8 \\
\hline 907,2 & & 612 & 120,0 & 129,7 & 125,2 & 123,7 & 122,4 & 121,8 & 119,9 \\
\hline 1310,4 & & 655 & 123,2 & 133,5 & 129,0 & 127,5 & 126,2 & 125,5 & 123,7 \\
\hline & 160 & & & & & & mutu SNI 2010 a & alah $143 \mathrm{~dB}$ & \\
\hline & 140 & & $=0$ & & & & & & \\
\hline 魚 & U & & $\therefore \Delta \cdot \Delta$ & & & & & & \\
\hline$\frac{\text { 量 }}{\mathrm{d}}$ & 10 & & & & & & 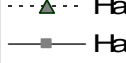 & dak 362. & \\
\hline$\frac{\pi}{5}$ & 80 & & & & & & $\because \mathrm{Ha}$ & dak 907 & \\
\hline 0 & 60 & & & & & & $\because-\mathrm{Ha}$ & dak 131 & \\
\hline & 40 & & & & & & & & \\
\hline & 20 & & & & & & & & \\
\hline & 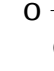 & 100 & 300 & 500 & 600 & 800 & & & \\
\hline
\end{tabular}

Gambar 2. TI bunyi ledakan pada beberapa variasi jumlah handak dan jarak. Data baku mutu dari SNI tahun 2010 (Anonim, 2010 ; Anonim, 2010 ${ }^{\mathrm{b}}$ ).

Sebagian dari taraf intensitas bunyi ledakan yang diakibatkan beberapa variasi jumlah bahan peledak pada jarak yang diinginkan pada Tabel 3, dapat diperlihatkan sebagaimana Gambar 2.

Bila hasil pengukuran TI bunyi ledakan pada Tabel 3 dan Gambar 2 dibandingkan dengan SNI 7570:2010 tentang Baku Tingkat Kebisingan pada
Kegiatan Pertambangan terhadap Lingkungan, di mana baku mutu tingkat kebisingan kelas 2 yang diakibatkan peledakan bernilai $110 \mathrm{~dB}$ A atau setara dengan $143 \mathrm{~dB}$ L, maka TI bunyi ledakan masih di bawah nilai baku mutu. Dengan demikian dapat diinterpretasikan bahwa penggunaan bahan peledak mulai dari 77,4 kg sampai 1310,4 kg tidak 
menimbulkan dampak kebisingan pada pemukiman warga di sekitar Gunung Sudamanik.

\section{KESIMPULAN}

Tingkat getaran tanah akibat peledakan pertambangan andesit masih di bawah baku mutu SNI 7571: 2010, yang berarti bahwa kegiatan peledakan tidak menyebabkan keretakan konstruksi rumah masyarakat pada lingkungan pemukiman yang berada di sekitar pertambangan andesit. Pengaruh kuantitas bahan peledak dan jarak secara simultan terhadap tingkat getaran tanah memenuhi persamaan berbentuk pecahan eksponen yang berbanding lurus jumlah maksimum delay bahan peledak berpangkat 0,8 dan berbanding terbalik jarak berpangkat 1,6 dengan koefisien pengali 365 . Instansi pemerintah sebagai regulator dan pihak perusahaan tambang dapat menggunakan persamaan (3) untuk memperkirakan jumlah maksimum pemakaian bahan peledak agar tingkat getaran tanah akibat peledakan masih di bawah baku mutu lingkungan.

Taraf intensitas bunyi ledakan akibat peledakan pertambangan andesit masih di bawah baku mutu SNI 7570: 2010, yang berarti bahwa kegiatan peledakan tidak menyebabkan kebisingan atau tidak mengganggu kenyamanan masyarakat pada pemukiman yang berada di sekitar pertambangan andesit. Pengaruh kuantitas bahan peledak yang sama dan jarak secara simultan terhadap taraf intensitas bunyi ledakan memenuhi persamaan berbentuk logaritma dari perbandingan jarak titik ledak ke tempat pemukiman masyarakat.

\section{DAFTAR PUSTAKA}

Amnieh, H.B., Mozdianfard, M.R., dan Siamaki, A., 2009. Predicting of Blasting Vibrations in Sarcheshmeh copper mine by Neural Network. Journal Safety Science, 48:319-325.

Anonim, 2010 a. Standar Nasional Indonesia Nomor 7570 tentang Baku Tingkat Kebisingan pada Kegiatan Pertambangan terhadap Lingkungan. Badan Standardisasi Nasional (BSN), Jakarta.

Anonim, $2010^{\mathrm{b}}$. Standar Nasional Indonesia Nomor 7571 tentang Baku Tingkat Getaran Peledakan pada Tambang Terbuka terhadap Bangunan. Badan Standardisasi Nasional (BSN), Jakarta.
Jullien, A., Proust, C., Martaud, T., Rayssac, E., dan Ropert, C., 2012. Variability in The Environmental Impacts of Aggregate Production. Journal Resources, Conservation and Recycling, 62:1-13.

Kartodharmo, M., 1990. Teknik Peledakan, Bandung, Laboratorium Geoteknik PAU Ilmu Rekayasa ITB.

Kecojevic, V., dan Radomsky, M., 2005. Flyrock Phenomena and Area Security in BlastingRelated Accidents. Journal Safety Science, 43:739-750.

Keraf, A.S., 2010. Etika Lingkungan Hidup, Jakarta, Penerbit Buku Kompas.

Marmer, D., Simangunsong G.M., dan Suwandhi, A., 2010. Peranan SNI 7571: 2010 dan SNI 7570: 2010 dalam kegiatan peledakan di tambang terbuka di Indonesia. Prosiding PPI Standardisasi, Jakarta, 11 Nop 2010. Perpustakaan Badan Standardisasi Nasional, hlm 1-15.

Sudarmono, D., 2008. Pengaruh Peledakan Terhadap Pit Wall dan Slope Design Pada Tambang Terbuka. Jurnal Rekayasa Sriwijaya, 17(3):23-31.

Sudarmono, D., Kadir, E., 2009. Pengukuran Vibrasi Hasil Peledakan di Tambang Terbuka Batu Hijau PT Newmont Nusa Tenggara. Jurnal Rekayasa Sriwijaya, 18(1):25-33.

Sudradjat, A., 2007. Otonomi Pengelolaan Sumberdaya Mineral dan Pengembangan Masyarakat, LPM Universitas Padjajaran. Bandung.

Sugandhy, A., dan Hakim R., 2007. Prinsip Dasar Kebijakan Pembangunan Berkelanjutan Berwawasan Lingkungan. Cetakan ke-2. Bumi Aksara. Jakarta.

Sugiyono, 2011. Metode Penelitian Kuantitatif Kualitatif dan $R \& D$. Cetakan ke-14, Penerbit Alfabeta. Bandung.

Sumardjono, M.S.W., Ismail, N., Rustiadi, E., dan Damai, A.A., 2011. Pengaturan Sumber Daya Alam di Indonesia: Antara yang Tersurat dan Tersirat. Gadjah Mada University Press. Yogyakarta.

Tippler, P.A., 1991. Fisika untuk Sains dan Teknik. Ed ke-3. Terjemahan dari: Physics for Scientists and Engineers. Prasetio, L., dan Adi, R.W. (penerjemah). Erlangga. Jakarta. 